\title{
Validated Hptlc Method for Simulteneous Determination of Cefoperazone Sodium and Sulbactam Sodium in Combined Dosage Form
}

\author{
Mr. Sanjay S. Malgundkar, Dr. Saira Mulla* \\ Shri Jjt University,Vidyanagari, Churu,Jhunjhunu Road,Chudela,District-Jhunjhunu, Rajasthan-333001
}

\begin{abstract}
A simple, accurate and precise HPTLC method for simultaneous estimation of Cefoperazone sodium and Sulbactam sodium as bulk and dry powder for injection in combined dosages form is described in this paper.

A mobile phase of Chloroform: Ethyl alcohol: Diethyl amine: Water (14: 16:8:1.2 v/v) was used after optimization at different concentrations for the development of densitogram. Aluminum plate coated with the silica Gel $60 F_{254}$ was used as stationary phase. Densitometric evaluation of the separated bands was performed at $274 \mathrm{~nm}$. The Rf values of Cefoperazone sodium and Sulbactam sodium were $0.41 \pm 0.01$ and $0.56 \pm$ 0.01 respectively.

The validated method was linear over the concentration range of $200 \mathrm{ng}$ to $900 \mathrm{ng} / \mathrm{spot}$ and $400 \mathrm{ng}$ to $1800 \mathrm{ng} / \mathrm{spot}$ of Cefoperazone sodium and Sulbactam sodium respectively. Precision of the method was evaluated by inerday and intraday RSD. The results were Cefoperazone sodium: Inter day RSD of peak response $1.25 \%$ and Intraday RSD $1.73 \%$ and for Sulbactam sodium Interday RSD of peak response $1.54 \%$ and Intraday RSD $0.98 \%$. Accuracy was determined in terms of percentage recovery at three concentration levels for Cefoperazone sodium RSD 99.20\%, 99.50\% and $100.32 \%$ and for sulbactam sodium RSD $101.25 \%$, $100.40 \%$ and $100.60 \%$ respectively. Specificity was determined by spectral analysis of cefoperazone sodium and sulbactam sodium and overlaying the standard spectra and sample spectra respectively.There was no any interference of mobile phase and diluents at the RF values of Cefoperazone sodium and sulbactam sodium. Validation was done in accordance with the ICH Guidelines.
\end{abstract}

Key words: High performance thin layer chromatography, microgram, nanogram, Cefoperazone sodium and Sulbactam sodium.

\section{Introduction}

Cefoperazone sodium is chemically Sodium $(6 R, 7 R)-7-[[(2 R)$-2-[[(4-ethyl-2,3-dioxopiperazin-1yl)carbonyl]amino]-2-(4- hydroxyphenyl)acetyl]amino]-3-[[(1-methyl-1 $H$-tetrazol-5-yl)sulphanyl]methyl]-8oxo- 5-thia-1-azabicyclo[4.2.0]oct-2-ene-2-carboxylate.Molecular weight of Cefoperazone is 668 and CAS No. is $62893-20-3$

It is Semi-synthetic product derived from a fermentation product. Cefoperazone is a third generation cephalosporin antibiotic. It is one of few cephalosporin antibiotics effective in treating Pseudomonas bacterial infections which are otherwise resistant to these antibiotics.

Cefoperazone exerts its bactericidal effect by inhibiting the bacterial cell wall synthesis, and sulbactam acts as a beta-lactamase inhibitor to increase the antibacterial activity of cefoperazone against beta-lactamase producing organisms. It is freely soluble in water, soluble in methanol, slightly soluble in ethanol ( 96 per cent).

Sulbactam sodium is chemically sodium $(2 S, 5 R)$-3, 3-dimethyl-7-oxo-4-thia-1-azabicyclo [3.2.0] heptane-2carboxylate 4, 4-dioxide. It is Semi-synthetic product derived from a fermentation product.

Sulbactam sodium is being used as Beta-lactam antibacterial. Molecular weight is 255.2 and CAS Number is 69388-84-7. It is freely soluble in water, sparingly soluble in ethyl acetate, very slightly soluble in ethanol (96 per cent). It is freely soluble in dilute acids.

Literature survey reveals that the several analytical methods viz. High performance liquid chromatography and UV-VIS spectrophotometric method have been reported for estimation of Cefoperazone sodium and Sulbactam sodium as an individual drug substance and in the combination drug products.

A simple, accurate and precise HPTLC method for simultaneous estimation of Cefoperazone sodium and Sulbactam sodium in the combined dosages form has been developed. 


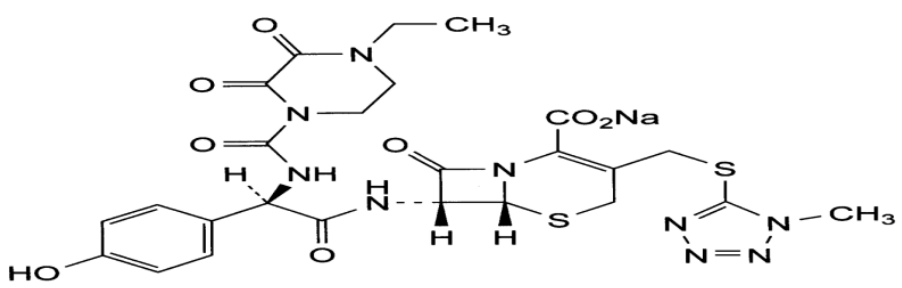

(a)

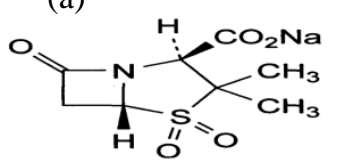

(b)

Figure 1. Structure of Cefoperazone Sodium (a) and Sulbactam Sodium (b)

\subsection{Chemicals and Reagents}

\section{Materials and Methods}

Cefoperazone sodium and Sulbactam sodium working standards were provided by Aurobindo Pharma Ltd through Mr. Vikrant Tamse as a noble gift samples for validation study. Dry powder injection samples required for method validation were procured from the market. All other reagents used during validation study were of analytical grade.

\subsection{Instrumentation}

The HPTLC method was optimized and validated on the CAMAG HPTLC instrument. CAMAG automatic TLC sampler 4 (ATS4) connected with the win CATS 4 software, CAMAG TLC SCANNER, Integrator controlled by win CATS4 software are the components of the HPTLC instrument. Precoated silica Gel $60 \mathrm{~F}_{254}$ on aluminium sheets were used as a stationary phase. During development of the plate CAMAG twin trough glass chamber with stainless steel lid was used.

In a $20 \times 10 \mathrm{~cm}$ twin trough glass chamber (Make: CAMAG), a linear ascending chromatographic development was carried out. During optimization of Method various solvents viz. n-butanol, methanol and water were used. However separation was not achieved. Hence method was optimized with other solvents like Chloroform, ethyl alcohol, diethyl amine and water in the different compositions. A method was optimized with the mobile phase of Chloroform: Ethyl alcohol: diethyl amine: water in the ratio (14: 16: 8:1.2 v/v). The chamber was saturated for 20 minutes. A deuterium lamp was used in the UV range of 190 to $400 \mathrm{~nm}$ as a source of radiation. A slit dimension was $6.00 \times 0.45 \mathrm{~mm}$, micro, scanning speed was $20 \mathrm{mms}^{-1}$ and data resolution at $100 \mu \mathrm{m} / \mathrm{step}$. Sample was spotted on the silica gel $60 \mathrm{~F}_{254}$ TLC plate by using CAMAG automatic TLC sampler-4 (ATS). The plates were developed in the CAMAG TLC chamber upto $80 \mathrm{~mm}$. Run time of the analysis was 25 minutes. After development, TLC plate was dried in a current of hot air with the help of hair dryer and dried on a CAMAG hot plate at $120^{\circ} \mathrm{C}$ for 5 minutes. The contents of Cefoperazone sodium and Sulbactam sodium were evaluated by comparing the peak areas with linear regression.

\section{Standard solution preparation}

$10 \mathrm{mg}$ of Cefoperazone sodium and $10 \mathrm{mg}$ of Sulbactam sodium standards were accurately weighed and transferred to separate $10 \mathrm{~mL}$ volumetric flasks. $2 \mathrm{~mL}$ of Methanol was added and sonicated for 5 minutes to dissolve the standards. Then diluted to $10 \mathrm{~mL}$ with methanol (Stock solution 1 and stock solution 2 for Cefoperazone sodium and Sulbactam sodium respectively) to obtain the concentration of $1 \mathrm{mg} / \mathrm{mL}$ and $1.0 \mathrm{mg}$ / $\mathrm{mL}$ or $1 \mu \mathrm{g} / \mu \mathrm{l}$ and $1 \mu \mathrm{g} / \mu \mathrm{l}$ of standard Cefoperazone sodium and Sulbactam sodium respectively.

\section{Sample solution preparation}

Label claim of Cefoperazone sodium and Sulbactam sodium in the combined dry powder injection in one unit was $1000 \mathrm{mg}$ and $1000 \mathrm{mg}$ respectively. To determine the content, 10 vial units were individually weighed. An average weight was recorded. Dry powder from all vials was mixed together to make a pooled sample. A sample weight equivalent to $1000 \mathrm{mg}$ of Cefoperazone and $1000 \mathrm{mg}$ of Sulbactam was weighed in $10 \mathrm{ml}$ volumetric flask. $2 \mathrm{~mL}$ of Methanol was added and sonicated for 5 minutes to dissolve. Finally diluted to $10 \mathrm{~mL}$ with methanol to obtain the concentration of $1 \mathrm{mg} / \mathrm{mL}$ and $1 \mathrm{mg} / \mathrm{mL}$ or $1 \mu \mathrm{g} / \mu \mathrm{l}$ and $1 \mu \mathrm{g} / \mu \mathrm{l}$ of Cefoperazone sodium and Sulbactam sodium respectively. 


\subsection{Validation of analytical method}

\section{Results and discussions}

ICH guideline was referred to validate an analytical method. Optimized analytical method was validated for specificity, linearity, accuracy, precision, LOD, LOQ and Robustness.

\subsubsection{Specificity}

In specificity, Cefoperazone sodium standard, Sulbactam sodium standard, sample solution, diluent and mobile phase were spotted on the TLC plate. TLC plate was developed in a twin trough CAMAG chamber referring the developed method. There was no any interference of mobile phase and diluent at the $R f$ value of Cefoperazone sodium and Sulbactam sodium. The separate spectrum of Cefoperazone and Sulbactam sodium were taken. Peak purity of Cefoperazone sodium and Sulbactam sodium was determined by comparing spectrum at three different regions of the spots. i.e Peak start ( S) Peak apex(M) and peak end(E) of both the drugs. The bands for Cefoperzone sodium and Sulbactam sodium were confirmed by comparing $R f$ values. The $R f$ values of Cefoperazone sodium and Sulbactam sodium were 0.41 and 0.58 respectively.

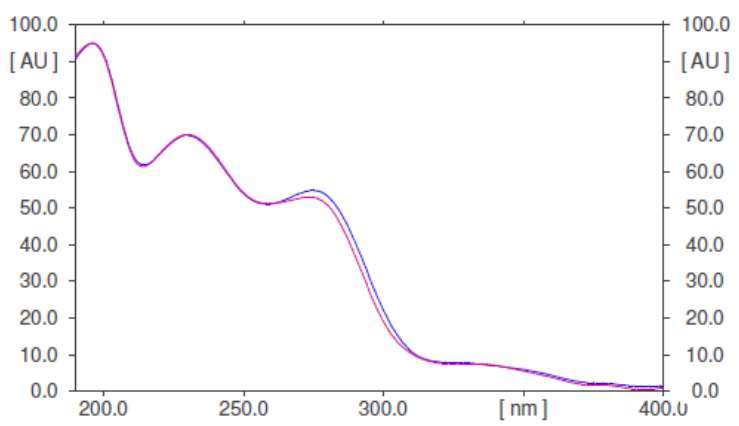

Figure 2. Overlaid spectrum of Cefoperazone sodium standard and Cefoperazone sodium sample

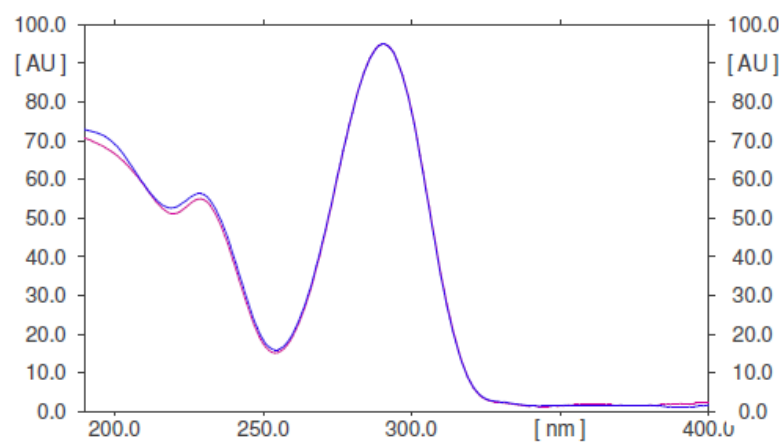

Figure 3. Overlaid spectrum of Sulbactam sodium standard and Sulbactam sodium sample Spectra comparison

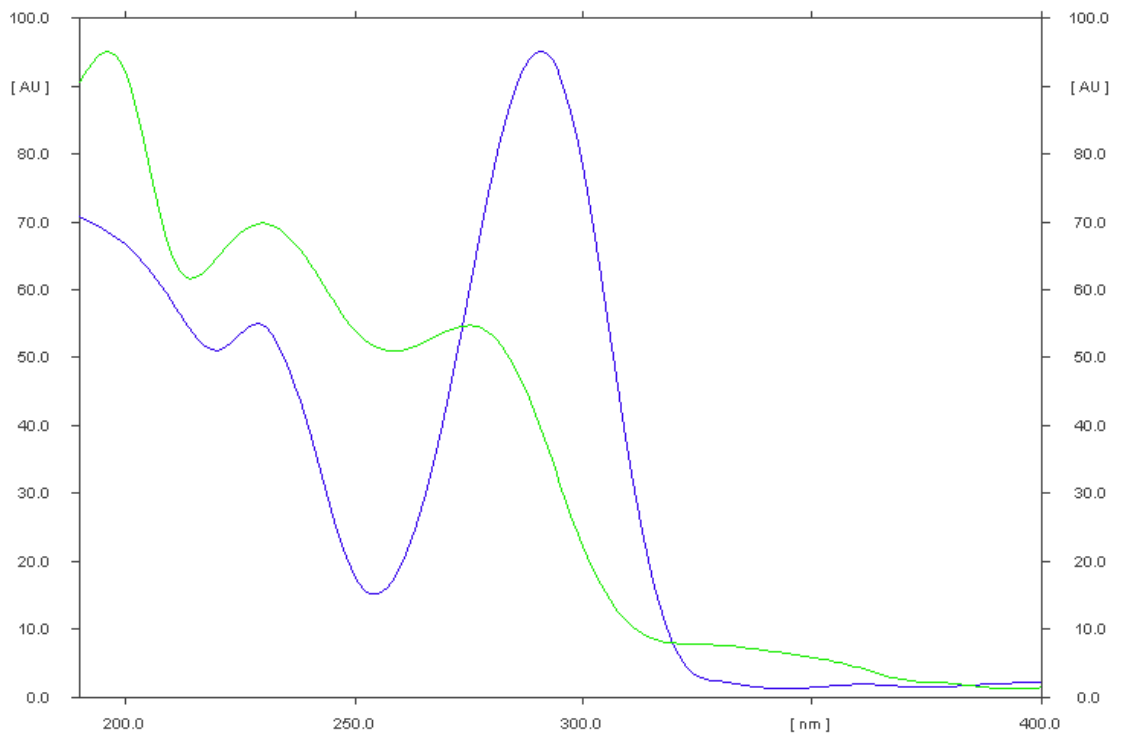

Figure 4. Overlaid spectrum of Cefoperazone Sodium standard and Sulbactam Sodium standard 


\subsubsection{Accuracy}

The accuracy of the Cefoperazone sodium and Sulbactam sodium was determined by performing recovery at three different concentration levels. The known concentrations of the samples were spiked with the standard cefoperazone and sulbactam in the concentrations of $400 \mathrm{ng}, 500 \mathrm{ng}$ and $600 \mathrm{ng}$ of cefoperazone and $800 \mathrm{ng}, 1000 \mathrm{ng}$ and $1200 \mathrm{ng}$ of sulbactam at $80 \% 100 \%$ and at 120 level with respect to the sample concentration. The spiked samples were analysed by following the proposed analytical method. The percentage recovery was calculated and was in the range of $99.20 \%$ to $100.32 \%$ for Cefoperozone and $100.40 \%$ to 101.60 $\%$ for sulbactam respectively. The results are tabulated as under:

Table 1. : Percentage Recovery of Cefoperazone sodium

$(\mathbf{n}=3)$

\begin{tabular}{|l|l|l|l|l|}
\hline $\begin{array}{c}\text { Sr. } \\
\text { No. }\end{array}$ & $\begin{array}{c}\text { Amount of std. Cefoperazone } \\
\text { sodium added in ng }\end{array}$ & $\begin{array}{c}\text { Amount of std. Cefoperazone } \\
\text { sodium recovered in ng }\end{array}$ & \% Recovery & $\begin{array}{c}\text { \% Relative } \\
\text { Standard Deviation }\end{array}$ \\
\hline 1 & 400 & 396.8 & 99.20 & 1.93 \\
\hline 2 & 500 & 497.5 & 99.52 & 1.88 \\
\hline 3 & 600 & 601.9 & 100.32 & 1.83 \\
\hline
\end{tabular}

Table 2: Percentage Recovery of Sulbactam sodium $(\mathbf{n}=3)$

\begin{tabular}{|l|l|l|l|l|}
\hline $\begin{array}{c}\text { Sr. } \\
\text { No. }\end{array}$ & \multicolumn{1}{|c|}{$\begin{array}{c}\text { Amount of std. Sulbactam } \\
\text { sodium added in ng }\end{array}$} & $\begin{array}{c}\text { Amount of std. Sulbactam } \\
\text { sodium recovered in ng }\end{array}$ & \% Recovery & $\begin{array}{c}\text { \% Relative } \\
\text { Standard Deviation }\end{array}$ \\
\hline 1 & 800 & 810 & 101.25 & 1.59 \\
\hline 2 & 1000 & 1004 & 100.40 & 0.21 \\
\hline 3 & 1200 & 1207.2 & 101.60 & 1.18 \\
\hline
\end{tabular}

\subsubsection{Precision}

The interday and intraday precision of the method were estimated by performing six determinations of Cefoperazone sodium and Sulbactam sodium standard solutions. The analysis was carried by referring the developed method. Analytical results obtained are tabulated as under:

Table 3: Precision for the Cefoperazone sodium

$(\mathrm{n}=6)$

\begin{tabular}{|l|l|l|l|l|}
\hline \multirow{2}{*}{$\begin{array}{l}\text { Conc. of the Cefoperazone sodium ( } \\
\text { ng/ band) }\end{array}$} & \multicolumn{2}{|c|}{ Inter-day precision } & \multicolumn{2}{c|}{ Intra-day precision } \\
\cline { 2 - 5 } & Mean area (AU) & \% RSD & Mean area (AU) & \% RSD \\
\hline 500 & 1583 & 1.25 & 1611 & 1.73 \\
\hline
\end{tabular}

Table 4: Precision for Sulbactam sodium

\begin{tabular}{|l|l|l|l|l|}
\multicolumn{4}{|c|}{ (n=6 ) } \\
\hline \multirow{2}{*}{$\begin{array}{l}\text { Conc. of the Sulbactam sodium } \\
\text { ( ng/ band) }\end{array}$} & \multicolumn{2}{|c|}{ Inter-day precision } & \multicolumn{2}{c|}{ Intra-day precision } \\
\cline { 2 - 5 } & Mean area (AU) & \% RSD & Mean area (AU) & \% RSD \\
\hline 1000 & 2788 & 1.54 & 2662 & 0.98 \\
\hline
\end{tabular}

\subsubsection{Robustness of the method}

During Robustness testing, small deliberate changes in the mobile phase composition were done. Effect on the results was examined. Mobile phase having different compositions were tried and chromatograms were run. The small change of $\pm 0.1 \mathrm{~mL}$ for each component of the mobile phase was done. Also $\pm 5 \%$ variation in the mobile during TLC development was used and chromatograph was run.

The robustness of the method was determined at three different concentration levels. The results are tabulated as under:

Table 5: Robustness testing

$(\mathbf{n}=\mathbf{3})$

\begin{tabular}{|c|c|c|c|c|c|c|}
\hline Parameter & $\begin{array}{l}\text { Conc. Level in } \\
\text { ng spot }^{-1} \text { of } \\
\text { Cefoperazone }\end{array}$ & $\begin{array}{c}\text { SD of Peak } \\
\text { response of } \\
\text { Cefoperazone }\end{array}$ & $\%$ RSD & $\begin{array}{c}\text { Conc. Level in ng } \\
\text { spot }^{-1} \text { of } \\
\text { Sulbactam }\end{array}$ & $\begin{array}{l}\text { SD of Peak } \\
\text { response of } \\
\text { Sulbactam }\end{array}$ & $\%$ RSD \\
\hline \multirow{3}{*}{$\begin{array}{l}\text { Mobile phase } \\
\text { composition } \\
( \pm 0.1 \mathrm{~mL})\end{array}$} & 400 & 29.14 & 1.15 & 800 & 42.72 & 1.17 \\
\hline & 500 & 25.0 & 0.77 & 1000 & 42.72 & 0.92 \\
\hline & 600 & 25.06 & 0.70 & 1200 & 52.55 & 0.97 \\
\hline \multirow{3}{*}{$\begin{array}{l} \pm 5 \% \text { variation in } \\
\text { mobile phase }\end{array}$} & 400 & 43.46 & 1.86 & 800 & 57.07 & 1.61 \\
\hline & 500 & 51.58 & 1.60 & 1000 & 76.16 & 1.66 \\
\hline & 600 & 23.45 & 0.65 & 1200 & 96.1 & 1.80 \\
\hline
\end{tabular}




\subsubsection{Linearity}

A series of standard solutions were prepared from the standard stock solutions of Cefoperazone sodium and Sulbactam sodium. Solutions were spotted on the TLC plate in the range of $0.2 \mu 1$ to $0.9 \mu 1$ of Cefoperazone sodium and $0.4 \mu \mathrm{l}$ to $1.8 \mu \mathrm{l}$ of Sulbactam sodium respectively. The corresponding concentrations were in the range of $0.2 \mu \mathrm{g} /$ spot to $0.9 \mu \mathrm{g} / \mathrm{spot}$ and $0.4 \mu \mathrm{g} / \mathrm{spot}$ to $1.8 \mu \mathrm{g} / \mathrm{spot}$ respectively. The linear Correlation coefficient for Cefoperazone sodium was 0.9989 and 0.9978 for Sulbactam sodium respectively.

\subsubsection{LOD and LOQ}

The limits of detection (LOD) and Limit of Quantitation (LOQ) were calculated from slopes of the calibration curve. The Limit of Detection and Limit of Quantitation obtained by this method for Cefoperazone sodium and Sulbactam sodium were $\mathrm{LOD}=2.067 \mathrm{mcg}, \mathrm{LOQ}=6.266 \mathrm{mcg}, \mathrm{LOD}=4.423 \mathrm{mcg}$ and $\mathrm{LOQ}=13.403$ mcg respectively.

\subsubsection{Analysis of drug product}

Experimental HPTLC results of the amount of Cefoperazone sodium and Sulbactam sodium in the dry powder Injectables expressed as a mg of label claim were in good agreement with the label claim. The drug content was found to be $99.5 \%$ and $100.9 \%$ for Cefoperazone and Sulbactam respectively.

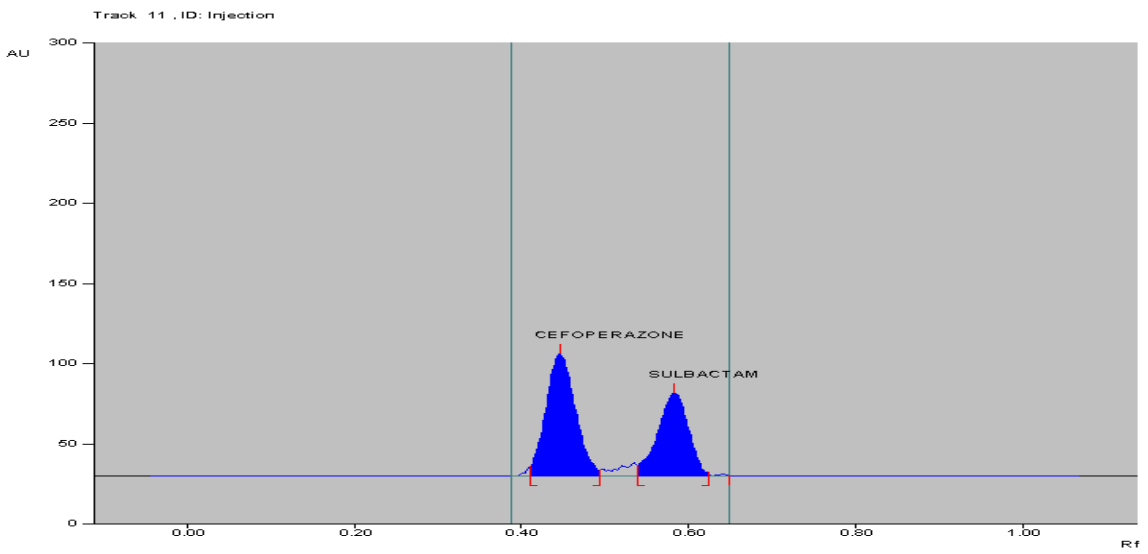

Figure 5. Densitogram of Cefoperazone sodium $\left(R_{F} 0.41\right)$ and Sulbactam sodium $\left(R_{F} 0.56\right)$

\subsubsection{Conclusion}

HPTLC analysis is rapidly becoming popular in routine analysis. The advantages of these analytical techniques are low operating cost and high sample throughput. This method may be used for simultaneous determination of Cefoperazone sodium and Sulbactam sodium in routine analysis in drug substances as well as drug products. This method may be used for degradation study of the Cefoperazone sodium and Sulbactam sodium. The proposed HPTLC method is simple, accurate, economically chief and reproducible.

\subsubsection{Acknowledgement}

The Authors are to Mr. Vikrant Tamse for providing the working standards required for the research work. The authors are thankful to M/s Anchrom Testlab Pvt. Ltd. Mulund ( E) ,Mumbai-400081 for providing their support to carry an Analytical work at their well established Laboratory.

\section{References}

[1]. Beckette A. H., Stenlake J.B., Practical Pharmaceutical Chemistry. The Anthlone Press; London, 4th edition, 157: 281-307 (1988).

[2]. Snyder L.R., Kirkland J.J., Glach J.L.,Practical HPLC Method Development. A Wiley Interscience Publication; London, $5^{\text {th }}$ edition, 402-420 (2005).

[3]. Rojer EB and Paul OM, Antimicrobial agents and Chemotherapy, 1986 Aug; p.231-3.

[4]. http://en.wikipedia.org/wiki/Cefoperazone

[5]. http://en.wikipedia.org/wiki/Sulbactam

[6]. Shah A.J. Adalard M.W.,Steriole J.D.:J. Pharm.Biomed.Anal.8,437 ( 1990)

[7]. Phapale PB, Lee HW, Kim SD, Lim MS, Kale DD et al. ( 2010) Analysis of Pazufloxacin mesilate in human plasma and urine by LC with Fluorescence and UV Detection and its application to pharmacokinetic study, chromatographia 71: 101-106

[8]. P.D. Sethi, Quantitative analysis of pharmaceutical applications 1997:3:23-65

[9]. Satindar Ahuja, Chromatography and separation science volume 4 of the separation science and technology series, 153-156.

[10]. ICH harmonized tripartite guideline -validation of analytical procedures: text and methodology -Q2(R1) Current Step 4 version ,Parent Guideline dated 27 October 1994 